\title{
Analisis Kualitas dan Penerapan Software Quality Assurance pada Situs Web e-Clinic Menggunakan Model ISO/IEC 9126
}

\author{
Tohirin ${ }^{1}$, Widhy Al Mauludyansah ${ }^{2}$, Sanjaya Endra Setyawan ${ }^{3}$, Septian Rheno Widianto ${ }^{4}$ \\ 1,2,3,4 Program Studi Pascasarjana \\ 1,2,3,4Magister Sistem Informasi STMIK LIKMI Bandung, Januari \\ 1'tohirin07@gmail.com, ${ }^{2}$ widhy.am@gmail.com, ${ }^{3}$ sanjayamaster@gmail.com, ${ }^{4}$ septian.rheno@yahoo.de
}

\begin{abstract}
Abstrak- Situs web merupakan salah satu media promosi profil perusahaan yang efektif dan banyak digunakan sekarang ini. Situs web yang baik memberikan peluang kepada sebuah instansi untuk mendapatkan pelanggan sebanyak-banyaknya. Eclinic merupakan sebuah aplikasi manajemen pasien klinik berbasis web guna membantu performa pelayanan dan olah data seperti pendaftaran dan pemeriksaan pasien, grafik dan laporan operasional harian maupun bulanan, GIS, dan lain-lain. Penelitian ini memiliki tujuan untuk mencari tahu mutu situs web e-Clinic menggunakan model ISO/IEC 9126. Penelitian ini diharapkan ias menjadi panduan bagi mereka yang ingin menerapkan model ISO/IEC 9126 dalam menganalisis kualitas dan penerapan Software Quality Assurance. Enam karakteristik yang diuji adalah terkait functionality, reliability, usability, efficiency, portability dan maintainability. Metode penelitian yang digunakan berupa analisis deskriptif dan induktif. Penelitian menghasilkan bahwa karakteristik functionality memiliki nilai 1, reliability memiliki nilai $\mathbf{8 8 , 8 2 \%}$, usability memiliki nilai 0,87 , efficiency memiliki nilai $D$ (64\%) menurut PageSpeed sedangkan nilai Yslow adalah E (54\%) dengan Fully Loaded Time adalah 8,4 detik, portability memiliki nilai 1 dan maintainability memenuhi standar karena menggunakan framework berbasis MVC. Berdasarkan hasil penelitian dibutuhkan improvisasi kualitas situs web e-Clinic pada kategori reliability dan efficiency.
\end{abstract}

Kata Kunci : SQA; eclinic; website; functionality; reliability; usability; efficiency; portability; maintainability

\section{PENDAHULUAN}

Perkembangan sistem dan teknologi informasi telah banyak membantu manusia, lebih khusus pengguna yang akan mencari banyak informasi lewat internet. Semakin meningkatnya pengguna internet dipengaruhi oleh semakin majunya teknologi internet dan telekomunikasi. Bulan Juni tahun 2019 diprediksi jumlah pengguna internet di Januari mencapai $59,71 \%$ dari total populasi Januari, yakni sebanyak 171.260 .000 pengguna [1].

Situs web merupakan bagian dari teknologi internet yang telah mengalami perkembangan begitu pesat. Penggunaan situs web dalam sebuah organisasi merupakan bagian dari modifikasi prosedur dan proses dengan pemanfaatan teknologi komputer agar tercipta pelayanan penuh manfaat bagi pengguna [2] . Atas dasar manfaat dan urgensinya dalam memenuhi keinginan dan kebutuhan pengguna maka kualitas dari sebuah situs web menjadi sangat perlu diperhatikan.

Eclinic (e-Clinic) adalah aplikasi manajemen pasien klinik berbasis web guna membantu performa pelayanan dan olah data seperti pendaftaran dan pemeriksaan pasien, grafik dan laporan operasional harian maupun bulanan, GIS, dan lain-lain. Eclinic menggunakan teknologi cloud computing sehingga tidak perlu diinstalasi di perangkat pengguna. Eclinic juga telah terintegrasi atau bridging dengan BPJS. Meningkatnya jumlah peselancar atau pengguna internet termasuk para pemilik instansi kesehatan dalam melakukan pencarian informasi yang cocok untuk instansi mereka, mengharuskan eClinic memiliki situs web yang berkualitas.

Mengingat belum tersedianya hasil penilaian kualitas situs web e-Clinic, maka dirasa perlu dilakukan penilaian kualitas melalui Software Quaity Assurane (SQA) pada situs web. Dalam memenuhi kualitas dan memastikan bahwa situs web telah sesuai harapan serta tujuan pengguna maka dibutuhkan penilaian kualitas situs web [3].

ISO/IEC 9126 merupakan salah satu model standarisasi penilaian kualitas produk sistem informasi atau perangkat lunak (SQA) yang diciptakan oleh Organisasi Standar Internasional. Kategori penilaian pada ISO/IEC 9126 meliputi 6 kategori, yakni fungsionalitas (functionality), efisiensi (efficiency), keandalan (reliability), kegunaan (usability), pemeliharaan (maintainability) dan portabilitas (portability). 
Hasil pengujian berupa nilai dari masingmasing faktor yang diuji kemudian dilakukan analisis dengan metode deskriptif dan pendekatan induktif. Hasil penelitian pada situs web diharapkan dapat dipakai sebagai rekomendasi dalam pengembangan situs web e-Clinic.

\section{A. Jaminan Perangkat Lunak (SQA)}

Jaminan perangkat lunak atau SQA merupakan rancangan serta ancangan sistematis terkait penilaian kualitas, standar produk, prosedur dan proses pada perangkat lunak [4]. Harapan dari jaminan perangkat lunak (SQA) adalah agar perangkat lunak yang dibangun bermutu tinggi.

\section{B. Model SQA ISO/IEC 9126}

Model SQA ISO/IEC 9126 termasuk bagian penting dalam menghasilkan keunggulan kompetitif bagi sebuah instansi dan termasuk hal yang fundamental dalam proses bisnis untuk menghasilkan produk maupun jasa. ISO/EIC adalah Organisasi Standarisasi Internasional yang mengembangkan standarisasi ISO/IEC 9126 guna mengevaluasi kualitas perangkat lunak [5].

Kualitas atau mutu dari kategori yang terdapat pada perangkat lunak diuraikan dalam ISO/IEC 9126. Semakin tinggi hasil penilaian kategori dan sub kategori yang dinilai dari sebuah perangkat lunak menunjukkan bahwa perangkat lunak tersebut memiliki kualitas tinggi.

Berdasarkan Gambar 1, faktor kualitas operasional perangkat lunak mencakup faktor kualitas fungsionalitas (functionality) adalah kemampuan perangkat lunak untuk memenuhi kebutuhan fungsional yang sudah ditentukan secara detail [6] ; efisiensi (efficiency) adalah ukuran seberapa banyak sumber daya komputasi dan baris kode program yang diperlukan sebuah perangkat lunak dalam menjalankan fungsinya [7]; keandalan (reliability) adalah seberapa mungkin sistem tahan terhadap kegagalan sistem [6]; kegunaan (usability) berhubungan kuat dengan kemudahan dalam pemakaian perangkat lunak [8] , pemeliharaan (maintainability) yaitu kemampuan untuk identifikasi dan perbaikan kesalahan pada komponen perangkat [8] . Dan portabilitas (portability) mengacu pada seberapa baik sebuah perangkat lunak dapat mengadopsi perubahan di lingkungan dan atau dengan persyaratannya [8].

\section{METODE PENELITIAN}

Urutan dari metode yang digunakan dalam penelitian ini adalah sebagaimana ditunjukkan oleh Gambar 2.

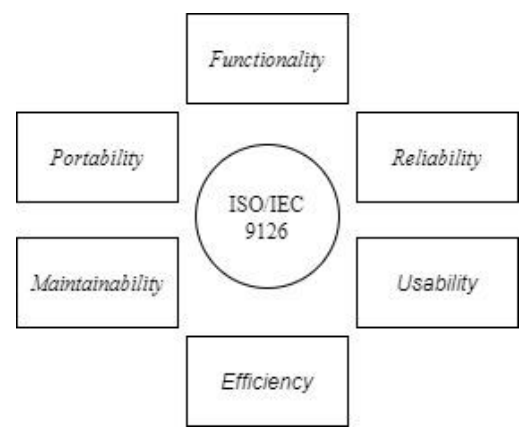

Gambar 1 Kategori ISO/IEC 9126
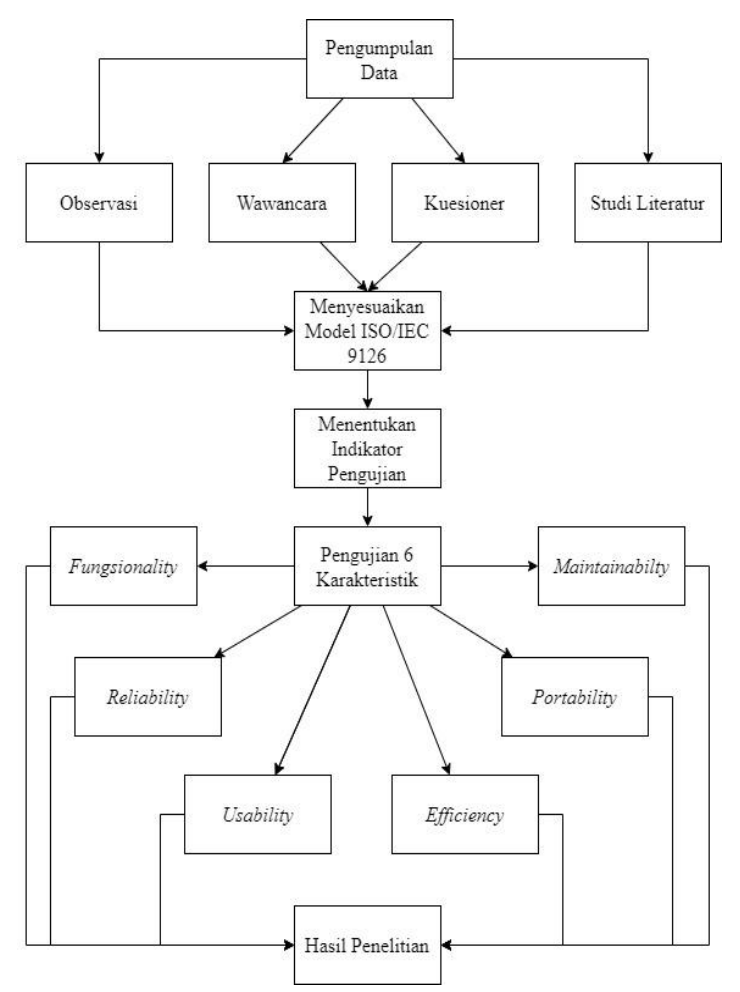

Gambar 2 Metodologi Penelitian

Objek penelitian terhadap situs web e-Clinic dengan karakteristik yang dinilai sesuai standar ISO/IEC 9126 yaitu fungsionalitas, keandalan, kebergunaan, efisiensi, pemeliharaan dan portabilitas. Karakteristik fungsionalitas diteliti dengan melibatkan responden sebanyak 3 kelompok di mana masing-masing kelompok berjumlah 5 orang. Karakteristik keandalan diteliti dengan metode constant menggunakan WAPT v10.0 yakni alat bantu untuk melakukan tes load, stres dan performa pada situs web. Karakteristik kebergunaan diteliti dengan kuesioner melibatkan 30 responden menggunakan USE Questionnaire yang merupakan standar kuesioner internasional dari STC Usability and User Experience Community. Karakteristik efisiensi diteliti dengan menggunakan situs web Gtmetrix yaitu alat bantu daring yang berguna untuk analisis tingkat efisiensi sebuah situs web. Karakteristik pemeliharaan diuji dengan cara 
wawancara dengan pengelola situs web e-Clinic. Sedangkan karakteristik portabilitas diteliti dengan akses situs web menggunakan 5 peramban terpopuler berdasarkan W3counter [9] baik di mode desktop maupun mobile.

\section{HASIL DAN PEMBAHASAN}

Hasil dari penelitian pada masing-masing karakteristik model SQA ISO/IEC 9126 berikutnya akan diberikan deskripsi.

\section{A. Functionality}

Uji functionality digunakan untuk mengetahui apakah situs web sesuai dengan kebutuhan pengguna. Berikut ini adalah instrumen untuk uji fungsionalitas situs web e-Clinic dengan melibatkan responden sebanyak 3 kelompok di mana masingmasing kelompok berjumlah 5 orang.

TABEL I. INSTRUMEN UJI FUNGSIONALITAS

\begin{tabular}{|c|c|c|}
\hline No & Fungsi & Pernyataan \\
\hline 1 & Halaman Utama & Berfungsi dengan benar \\
\hline 2 & Halaman Tentang & Berfungsi dengan benar \\
\hline 3 & Halaman Fitur & Berfungsi dengan benar \\
\hline 4 & Halaman Klien & Berfungsi dengan benar \\
\hline 5 & Halaman Kontak & Berfungsi dengan benar \\
\hline 6 & Tautan Google Maps & Berfungsi dengan benar \\
\hline 7 & Tautan Telepon & Berfungsi dengan benar \\
\hline 8 & Tautan Email & Berfungsi dengan benar \\
\hline 9 & Search & berfungsi dengan benar \\
\hline 10 & Download & Berfungsi dengan benar \\
\hline 11 & Register & Berfungsi dengan benar \\
\hline 12 & Login Patien & Berfungsi dengan benar \\
\hline 13 & Login Clinic & Berfungsi dengan benar \\
\hline 14 & Register via Facebook & Berfungsi dengan benar \\
\hline 15 & Register via Google & Berfungsi dengan benar \\
\hline 16 & Login via Facebook & Berfungsi dengan benar \\
\hline 17 & Login via Google & Berfungsi dengan benar \\
\hline
\end{tabular}

TABEL II. REKAPITULASI UJI FUNGSIONALITAS

\begin{tabular}{|c|c|c|}
\hline No Pernyataan & Lolos & Tidak Lolos \\
\hline 1 & 3 & 0 \\
\hline 2 & 3 & 0 \\
\hline 3 & 3 & 0 \\
\hline 4 & 3 & 0 \\
\hline 5 & 3 & 0 \\
\hline 6 & 3 & 0 \\
\hline 7 & 3 & 0 \\
\hline 8 & 3 & 0 \\
\hline 9 & 3 & 0 \\
\hline 10 & 3 & 0 \\
\hline 11 & 3 & 0 \\
\hline 12 & 3 & 0 \\
\hline 13 & 3 & 0 \\
\hline
\end{tabular}

\begin{tabular}{|c|c|c|}
\hline 14 & 3 & 0 \\
\hline 15 & 3 & 0 \\
\hline 16 & 3 & 0 \\
\hline 17 & 3 & 0 \\
\hline Total & $\mathbf{5 1}$ & $\mathbf{0}$ \\
\hline
\end{tabular}

Untuk menghitung nilai fungsionalitas dengan menggunakan persamaan (1) [10]

$$
X=1-(A / B)
$$

dimana A adalah total fungsi yang tidak sesuai dan $\mathrm{B}$ adalah total fungsi yang dievaluasi.

Dari persamaan (1) diperoleh hasil sebagaimana berikut:

$\mathrm{X}=1-(0 / 51)$

$\mathrm{X}=1$

Berdasarkan hasil perhitungan di atas dapat disimpulkan bahwa situs web tersebut memiliki tingkat fungsionalitas yang baik sesuai standar ISO/IEC 9126 yaitu apabila nilai $\mathrm{X}$ mendekati 1 ( 0 $\leq \mathrm{X} \leq 1)[10]$.

\section{B. Reliability}

Uji reliability menggunakan perangkat lunak WAPT v10.0 yakni alat bantu untuk melakukan tes load, stres dan performa pada situs web. Pengujian dilakukan dengan metode constant yang artinya jumlah virtual user ketika tes dilakukan tidak berubah-ubah. Jumlah pengguna sebanyak 5 user dan waktu pengujian selama 10 menit.

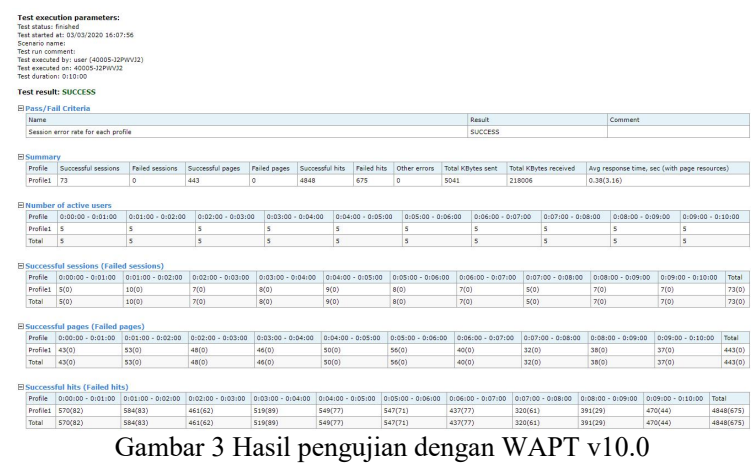

Pada laporan yang dihasilkan dijelaskan untuk kategori session dari total 73 session yang aktif terdapat session sukses sebanyak 73 kali dan session gagal sebanyak 0 kali. Kategori akses halaman dari total 443 halaman diakses terdapat halaman sukses sebanyak 443 kali dan halaman gagal sebanyak 0 kali. Kategori hit dari total 5.523 hit terdapat hit sukses sebanyak 4.848 dan hit gagal sebanyak 675 .

Total pengujian untuk ketiga kategori tersebut (session, halaman dan hit) adalah 6.039 kali dengan rincian sebanyak 5.364 kali hasil uji sukses dan 675 
kali hasil uji gagal. Persamaan reliability menggunakan model Nelson [11] dengan persamaan (2).

$$
\mathrm{R}=(A / B) / A
$$

dimana A adalah total hasil pengujian dan B adalah total hasil pengujian gagal.

Berdasarkan persamaan tersebut dapat diperoleh nilai reliability sebagaimana berikut.

$\mathrm{R}=(6.039 / 675) / 6.039$

$\mathrm{R}=88,82 \%$

Menurut Telcordia, standar reliability perangkat lunak minimal bernilai 95\% [12] . Itu berarti nilai reliability situs web e-Clinic belum memenuhi standar minimal.

\section{Usability}

Uji usability menggunakan kuesioner yang telah menjadi standar internasional yaitu USE Questionnaire yang dikembangkan STC Usability and User Experience Community dari Arnold M.Lund [13]. Terdapat 4 komponen uji yaitu Usefulness, Ease of Use, Easy of learning dan Satisfication. Berikut instrumen uji usability.

TABEL III. INSTRUMEN USABILITY

\begin{tabular}{|c|l|}
\hline No & \multicolumn{1}{|c|}{ Pertanyaan } \\
\hline \multicolumn{2}{|c|}{ Kegunaan } \\
\hline 1 & Sistem membantu saya menjadi lebih efektif \\
\hline 2 & Sistem membantu saya menjadi lebih produktif \\
\hline 3 & Sistem bermanfaat \\
\hline 4 & Sistem membantu menyelesaikan tugas saya \\
\hline 5 & $\begin{array}{l}\text { Sistem membuat hal-hal yang ingin saya capai } \\
\text { lebih mudah dilakukan }\end{array}$ \\
\hline 6 & $\begin{array}{l}\text { Sistem menghemat waktu saya saat } \\
\text { menggunakannya }\end{array}$ \\
\hline 7 & Sistem ini sesuai dengan kebutuhan saya \\
\hline 8 & Sistem ini bekerja sesuai apa yang saya harapkan \\
\hline \multicolumn{2}{|c|}{ Kemudahan penggunaan } \\
\hline 9 & Sistem mudah digunakan \\
\hline 10 & Sistem praktis digunakan \\
\hline 11 & Sistem mudah dipahami pengguna \\
\hline 12 & Langkah pengoperasian sistem tidak rumit \\
\hline 13 & Sistem dapat disesuaikan dengan kebutuhan \\
\hline 14 & Menggunakannya mudah/tidak perlu susah payah \\
\hline 15 & Saya dapat menggunakan tanpa instruksi tertulis \\
\hline 16 & Saya tidak menemukan ketidakkonsistenan \\
\hline 17 & Semua pengguna akan menyukai sistem ini \\
\hline & \multicolumn{1}{|c|}{ Kemudahan dipelajari } \\
\hline 18 & $\begin{array}{l}\text { Saya mengatasi kesalahan dengan cepat dan } \\
\text { mudah }\end{array}$ \\
\hline 19 & Saya menggunakannya dengan lancar setiap saat \\
\hline 20 & Saya belajar menggunakannya dengan cepat \\
\hline 21 & Saya mudah mengingat cara menggunakannya \\
\hline 22 & Cara penggunaan sistem mudah dipelajari \\
\hline
\end{tabular}

\begin{tabular}{|c|l|}
\hline No & \multicolumn{1}{|c|}{ Pertanyaan } \\
\hline 23 & Saya dengan cepat dapat terampil dengan sistem \\
\hline \multicolumn{2}{|c|}{ Kepuasan } \\
\hline 24 & Saya puas dengan sistem ini \\
\hline 25 & Saya akan merekomendasikan kepada rekan \\
\hline 26 & Sistem menyenangkan untuk digunakan \\
\hline 27 & Sistem bekerja seperti yang saya inginkan \\
\hline 28 & Sistem sangat bagus \\
\hline 29 & Saya rasa harus memiliki/menggunakannya \\
\hline 30 & Saya pikir bakal sering menggunakan sistem ini \\
\hline
\end{tabular}

Hasil uji usability menggunakan kuesioner USE terhadap 30 responden terdapat pada tabel berikut.

TABEL IV. REKAPITULASI UJI USABILITY

\begin{tabular}{|c|c|c|c|c|c|}
\hline Pertanyaan & SS & $\mathbf{S}$ & KS & TS & STS \\
\hline 1 & 20 & 10 & 0 & 0 & 0 \\
\hline 2 & 12 & 17 & 1 & 0 & 0 \\
\hline 3 & 14 & 15 & 1 & 0 & 0 \\
\hline 4 & 14 & 14 & 2 & 0 & 0 \\
\hline 5 & 12 & 16 & 2 & 0 & 0 \\
\hline 6 & 15 & 12 & 3 & 0 & 0 \\
\hline 7 & 11 & 14 & 5 & 0 & 0 \\
\hline 8 & 12 & 14 & 4 & 0 & 0 \\
\hline 9 & 14 & 16 & 0 & 0 & 0 \\
\hline 10 & 16 & 14 & 0 & 0 & 0 \\
\hline 11 & 15 & 13 & 2 & 0 & 0 \\
\hline 12 & 12 & 16 & 2 & 0 & 0 \\
\hline 13 & 8 & 18 & 4 & 0 & 0 \\
\hline 14 & 15 & 13 & 2 & 0 & 0 \\
\hline 15 & 12 & 15 & 3 & 0 & 0 \\
\hline 16 & 14 & 13 & 3 & 0 & 0 \\
\hline 17 & 12 & 16 & 2 & 0 & 0 \\
\hline 18 & 14 & 14 & 2 & 0 & 0 \\
\hline 19 & 13 & 16 & 1 & 0 & 0 \\
\hline 20 & 15 & 15 & 0 & 0 & 0 \\
\hline 21 & 15 & 13 & 2 & 0 & 0 \\
\hline 22 & 15 & 15 & 0 & 0 & 0 \\
\hline 23 & 13 & 17 & 0 & 0 & 0 \\
\hline 24 & 15 & 14 & 1 & 0 & 0 \\
\hline 25 & 12 & 16 & 2 & 0 & 0 \\
\hline 26 & 12 & 14 & 4 & 0 & 0 \\
\hline 27 & 14 & 15 & 1 & 0 & 0 \\
\hline 28 & 14 & 14 & 2 & 0 & 0 \\
\hline 29 & 13 & 14 & 3 & 0 & 0 \\
\hline 30 & 18 & 11 & 1 & 0 & 0 \\
\hline Total & 411 & 434 & 55 & 0 & 0 \\
\hline
\end{tabular}

TABEL V. TOTAL SKOR DARI REKAPITULASI UJI USABILITY

\begin{tabular}{|c|c|c|c|}
\hline Respons & Jumlah & Skor & Jumlah x Skor \\
\hline SS & 411 & 5 & 2055 \\
\hline S & 434 & 4 & 1736 \\
\hline KS & 55 & 3 & 165 \\
\hline TS & 0 & 2 & 0 \\
\hline STS & 0 & 1 & 0 \\
\hline \multicolumn{4}{|c|}{ Total skor } \\
\hline
\end{tabular}


Untuk menghitung nilai usability menggunakan persamaan (3). Sedangkan skor maksimal ditunjukkan dengan persamaan (4).

$$
\begin{aligned}
& \mathrm{U}=\mathrm{P} / \mathrm{Q} \\
& \mathrm{Q}=\mathrm{R} \times \mathrm{S} x 5
\end{aligned}
$$

Di mana U adalah usability, $\mathrm{P}$ adalah skor total, $\mathrm{Q}$ adalah skor maksimal, $\mathrm{R}$ adalah jumlah semua responden yang menjawab Sangat Setuju (nilai $=5$ ) dan $\mathrm{S}$ adalah jumlah soal. Dari persamaan tersebut dapat diperoleh nilai skor maksimal dan usability sebagai berikut:

$$
\begin{aligned}
\text { Skor maksimal } & =30 \times 30 \times 5 \\
& =4500 \\
\text { Nilai usability } & =3956 / 4500 \\
& =0,87
\end{aligned}
$$

Semakin mendekati 1 maka nilai semakin baik [10]. Berdasarkan hasil perhitungan didapatkan nilai 0,87 yang artinya nilai tersebut mendekati nilai 1 sehingga dapat dikatakan baik.

\section{Efficiency}

Pengujian matriks pada efficiency merupakan ukuran seberapa banyak sumber daya komputasi dan baris kode program yang diperlukan sebuah perangkat lunak dalam menjalankan fungsinya [7] . Uji efficiency pada e-Clinic dilakukan dengan menggunakan situs web Gtmetrix dengan hasil seperti gambar berikut.

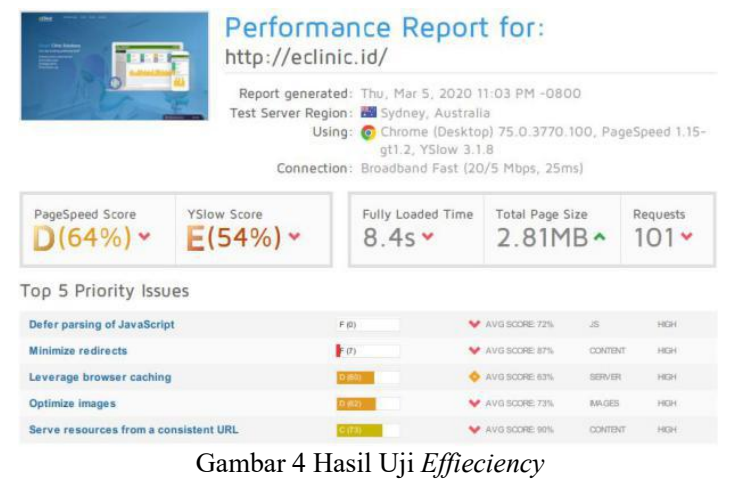

Pada laporan performa yang dihasilkan untuk situs web e-Clinic nilai menurut PageSpeed adalah D (64\%) sedangkan Yslow adalah E (54\%) dengan Fully Loaded Time adalah 8,4 detik, Total Page Size adalah 2,81 MB dan Request sebanyak 101 kali.

Dapat disimpulkan bahwa secara umum performa situs web buruk, di mana menurut situs web Gtmetrix jika skor di bawah C (situs web eClinic memiliki skor D dan E) berarti ada beberapa konfigurasi dalam situs web yang tidak sesuai dengan best practice. Menurut studi yang dilakukan Gtmetrix bahwa pengguna akan meninggalkan situs web jika tidak dapat menampilkan halaman dalam waktu 4 detik sedangkan situs web e-Clinic dengan beban 101 request, situs web membutuhkan waktu 8.4 detik untuk bisa diakses (Fully Loaded Time sebesar 8,4 detik). Sedangkan untuk ukuran situs web tergolong kecil yaitu 2,82 MB.

Terdapat 5 isu prioritas yang dapat dioptimasi oleh pemilik situs web untuk meningkatkan performa diataranya adalah sebagai berikut:

- Defer parsing of javascript mendapatkan nilai $\mathrm{F}$ disarankan untuk optimasi agar mengurangi hambatan dalam proses menampilkan halaman situs web.

- Minimize redirects mendapatkan nilai F disarankan untuk optimasi dengan menghapus redirects ke halaman luar situs web jika dimungkinkan.

- Leverage browser caching mendapatkan nilai D disarankan untuk optimasi beberapa resource yang bisa disimpan di cache

- Optimize Images mendapatkan nilai D disarankan untuk optimasi dengan mengurangi ukuran beberapa image aset

- Serve resources from a consistent URL mendapatkan nilai $\mathrm{C}$ disarankan untuk optimasi resource yang memiliki kesamaan konten tetapi berbeda URL akses.

\section{E. Portability}

Sebuah perangkat lunak dikatakan portabel apabila biaya memindahkannya (migrasi dan adaptasi) pada lingkungan baru jauh lebih minim jika dibandingkan dengan biaya membangun dari awal [14] . Uji portability pada situs web e-Clinic dilakukan dengan menggunakan peramban desktop dan mobile. Peramban yang digunakan adalah 5 besar aplikasi peramban terpopuler berdasarkan situs web W3counter pada bulan Februari tahun 2020 yaitu Chrome, Safari, Internet Explorer \& Edge, Firefox dan Opera. Untuk peramban mobile yang digunakan adalah lingkungan OS Android.

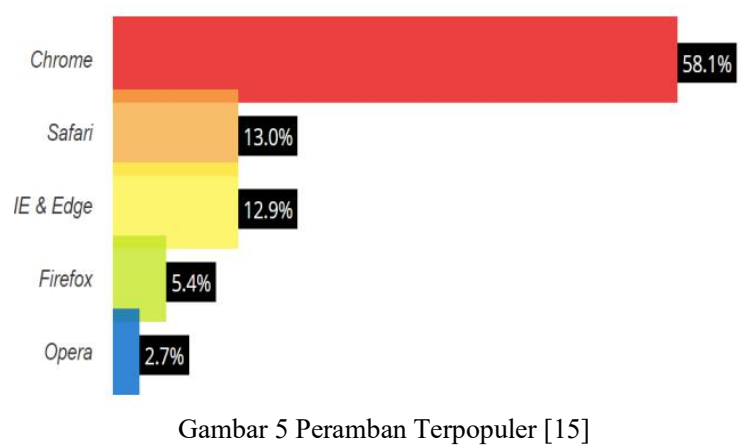


TABEL VI. HASIL UJI PORTABILITY

\begin{tabular}{|c|c|c|c|}
\hline \multirow{2}{*}{ No } & \multirow{2}{*}{ Peramban } & \multicolumn{2}{|c|}{ Akses } \\
\cline { 3 - 4 } & & Desktop & Android \\
\hline 1 & Chrome & OK & OK \\
\hline 2 & Safari & OK & OK \\
\hline 3 & Internet Explorer \& Edge & OK & OK \\
\hline 4 & Firefox & OK & OK \\
\hline 5 & Opera & OK & OK \\
\hline
\end{tabular}

Berdasarkan hasil pengujian didapatkan bahwa semua halaman pada situs web dalam berjalan dengan baik pada kelima peramban tersebut baik aplikasi untuk desktop maupun mobile dengan OS Android. Dapat disimpulkan untuk uji portability mendapatkan nilai 1 .

\section{F. Maintainabilty}

Berdasarkan wawancara dengan pengelola situs web, diketahui bahwa e-Clinic dikembangkan dengan menggunakan kerangka kerja CodeIgniter. CodeIgniter adalah kerangka kerja open source berbahasa PHP menggunakan konsep MVC yang menyediakan banyak library untuk koneksi ke basis data dan banyak operasi lainnya seperti mengirim pesan elektronik, unggah lampiran, pengelolaan session.

MVC merupakan kependekan dari Model View Controller yaitu sebuah konsep pembuatan aplikasi di mana data, logika proses dan tampilan situs web dipisahkan. Model berperan untuk menangani interaksi aplikasi dan basis data, view menangani logika program dan controller menangani interaksi view dan model [16]. Kelebihan yang ditawarkan MVC di antaranya dapat bekerja secara independen tanpa banyak mengandalkan komponen lain, komponen Model pada MVC dapat dilakukan tes terpisah oleh pengguna, pengembangan komponen dapat dilakukan paralel, mendukung pengembangan aplikasi berbasis test driven. Hal tersebut memudahkan dalam pemeliharaan, pengujian dan peningkatan versi yang berarti telah memenuhi salah satu unsur maintainability.

\section{KESIMPULAN}

Analisis kualitas dan penerapan Software Quality Assurance pada situs web e-Clinic dengan model ISO/IEC 9126 telah dilakukan terhadap 6 kategori di mana berdasarkan penelitian terdapat 4 kategori yang telah memenuhi standar yaitu :

- Functionality, unsur kebutuhan pelanggan telah terpenuhi di mana semua fungsi yang diharapkan bernilai 1 .

- Usability, tingkat kepuasan pelanggan terhadap sistem senilai 0,87 .
- Portability, unsur kemampuan sistem beradaptasi dalam lingkungan dan peramban yang berbeda mendapatkan nilai sebesar 1 .

- Maintainability, situs web dikembangkan dengan framework yang sudah mendukung kemudahan dalam pemeliharaan, pengujian dan peningkatan versi.

Adapun 2 kategori yang belum memenuhi standar atau perlu peningkatan performa yaitu:

- Reliability, memperoleh nilai sebesar 88,82\%, di mana nilai tersebut belum memenuhi standar minimal menurut Telcordia yaitu 95\%.

- Efficiency, memperoleh nilai PageSpeed di angka D (64\%), Yslow di angka E (54\%) dan Fully Loaded Time selama 8,4 detik. Nilai tersebut tidak masuk acuan standar Gtmetrix yaitu PageSpeed dan Yslow minimal bernilai C sedangkan Fully Loaded Time minimal 4 detik.

Situs web yang baik memberikan peluang kepada sebuah instansi untuk mendapatkan pelanggan sebanyak-banyaknya. Untuk itu, sebagai saran, keandalan (reliability) dan efisiensi (efficiency) harus ditingkatkan agar seluruh kategori pada ISO/IEC 9126 terpenuhi, sehingga situs web eClinic benar-benar menjadi media promosi yang ampuh bagi perusahaan yang bersangkutan.

\section{REFERENS}

[1] "Asia Internet Stats by Country and 2020 Population Statistics," Miniwatts Marketing Group, Januari 2020. [Online]. Available: https://www.internetworldstats.com/asia.htm\#id. [Diakses 3 Januari 2020].

[2] I. P. A. E. Pratama, ECommerce, E-Business Dan Mobile Commerce Berbasis Open Source, Bandung: Informatika, 2015.

[3] M. Rochmani, E. Darwiyanto dan D. D. J. Suwawi, "Evaluasi Website Akademik Menggunakan ISO/IEC 9126," eProceedings of Engineering, vol. 2, pp. 1756-1761, 2015.

[4] C. S. Murugan dan S. Prakasam, "A Literal Review of Software Quality Assurance," Januari Journal of Computer Applications, pp. 13511-1279, 2013.

[5] V. A. K. Siren, N. Y. Setiawan dan R. I. Rokhmawati, "Evaluasi Kualitas Perangkat Lunak Menggunakan ISO/IEC 9126-4 Quality," Jurnal Pengembangan Teknologi Informasi dan Ilmu Komputer, pp. 1625-1632, 2019.

[6] C. Juliane, R. Dzulkarnaen dan W. Susanti, "Metode McCall's untuk Pengujian Kualitas Sistem Informasi Administrasi Tugas Akhir (SIATA)," JURNAL RESTI, vol. 3, no. 3, pp. 488 - 495, 2019.

[7] B. Sugiantoro dan M. Mustakim, "Analisa Usabilitas Sistem Deteksi Akses Pornografi Pengguna Internet Menggunakan Metode McCall'S," JOIN, vol. 2, pp. 56-62, 2017.

[8] I. Fleming, "Software Quality Attributes," 23 November 2019. [Online]. Available: http://www.sqa.net/iso9126.html. [Diakses 5 Februari 2020].

[9] "Browser \& Platform Market Share," w3 counter, Februari 2020. [Online]. Available: 
http://www.w3 counter.com/globalstats.php. [Diakses 3 March 2020].

[10] Y. Fitrisia dan M. Fadhly, "Evaluasi Functionality dan Usability External Quality Sistem Informasi Proyek Akhir Politeknik Caltex Riau," Jurnal Politeknik Caltex Riau, vol. 3, no. 193-202, 2017.

[11] T. N. Sari, "Analisis Kualitas dan Pengembangan Sistem Informasi Akademik Berbasis Web Menggunakan Standard ISO 9126," Jurnal Informatika dan Komputer, vol. 1, no. 1, 2016.

[12] A. Asthana dan J. Olivieri, "Quantifying Software Reliability," dalam 2009 IEEE Januari Workshop Technical Committee on Communications Quality and Reliability, 2009.

[13] A. M. Lund, "Measuring Usability with the USE Questionnaire," Januari 2001. [Online]. Available:
https://www.researchgate.net/publication/230786746_Meas uring_Usability_with_the_USE_Questionnaire. [Diakses 3 March 2020].

[14] A. Hidayati, E. Oktariza, F. Rosmaningsih dan S. A. Lathifah, "Analisa Kualitas Perangkat Lunak Sistem Informasi Akademik Menggunakan McCall," JURNAL MULTINETICS, vol. 3, pp. 47-51, 2017.

[15] "W3Counter: Global Web Stats - Browser \& Platform Market Share," Awio Web Services LLC, [Online]. Available: https://www.w3 counter.com/globalstats.php. [Diakses 5 February 2020].

[16] S. Hasyrif dan Rismayani, "Penerapan Konsep MVC Pada Aplikasi Web Menggunakan Framework Laravel," Prosiding Seminar Ilmiah Sistem Informasi dan Teknologi Informas, vol. V, pp. 174-183, 2016. 